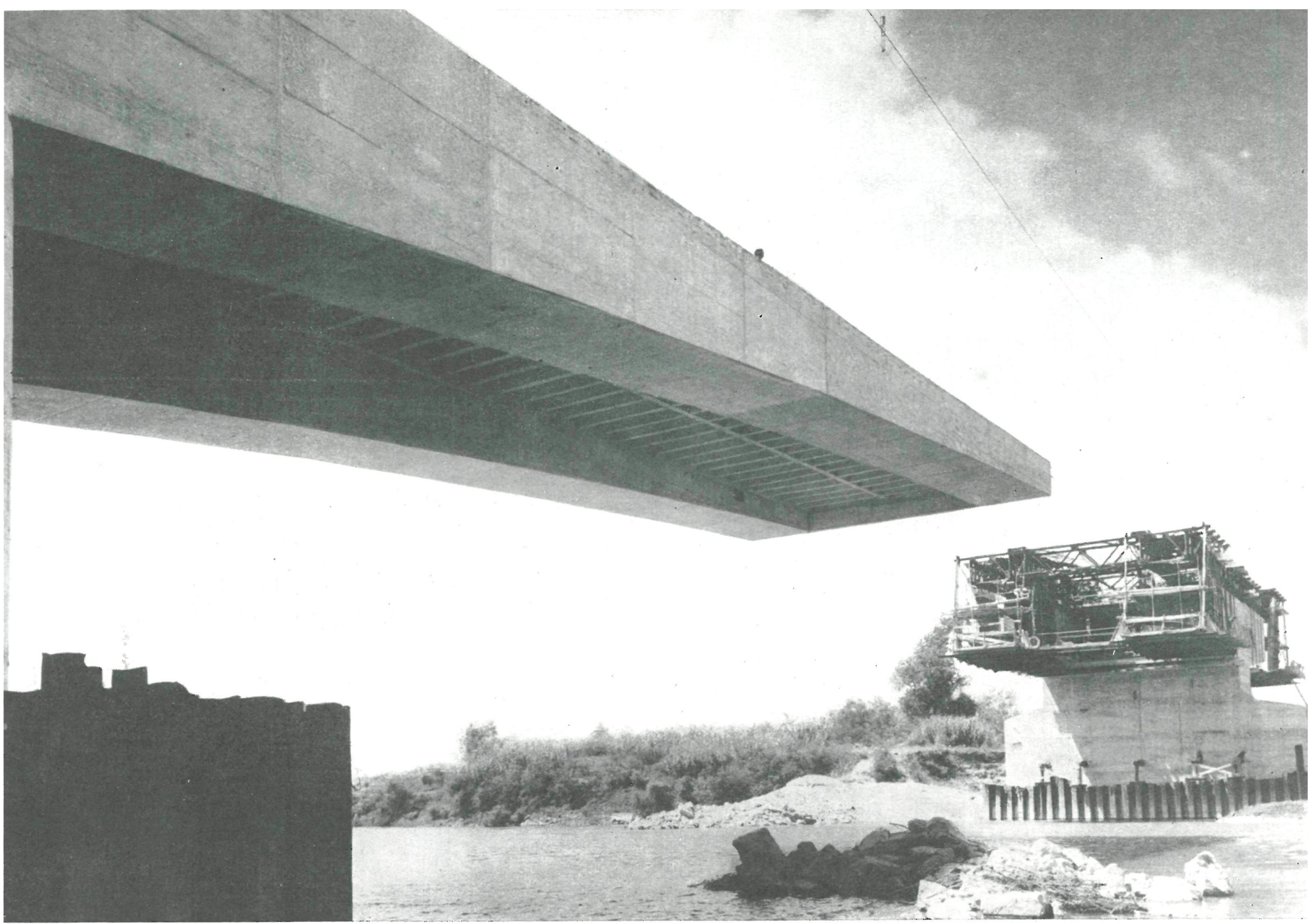

\title{
puente Beaucaire sobre el río Ródano
}

Información amablemente facilitada por la Sociedad de Grands Travaux de Marseille.

El puente Beaucaire, de $462 \mathrm{~m}$ de longitud total, es una estructura de hormigón pretensado, de cinco tramos de $81,20 \mathrm{~m}$ de luz cada uno. El puente salva el río Ródano y une la aglomeración de Beaucaire con la de Tarascón (Francia), siguiendo el trazado de la carretera nacional número 99. La anchura total es de $13 \mathrm{~m}$, de los que se han reservado cuatro para los dos andenes de dos metros de anchura.

La obra es del tipo hiperestático y presenta las características siguientes:

a) El tablero se ha empotrado en las pilas, las que, a su vez, se hallan en la misma condición respecto a los cimientos.

b) Cada tramo dispone de una articulación, de acero moldeado, que sólo permite la transmisión de reacciones verticales.

c) Los estribos se han dispuesto para equilibrarse con la ménsula que soportan.

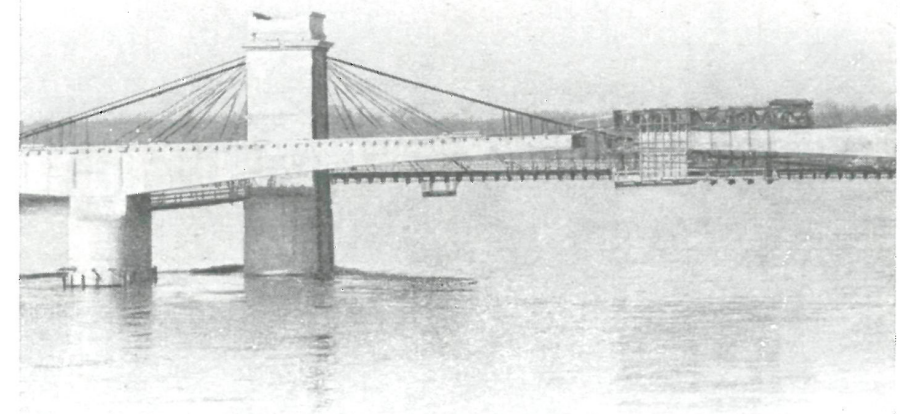



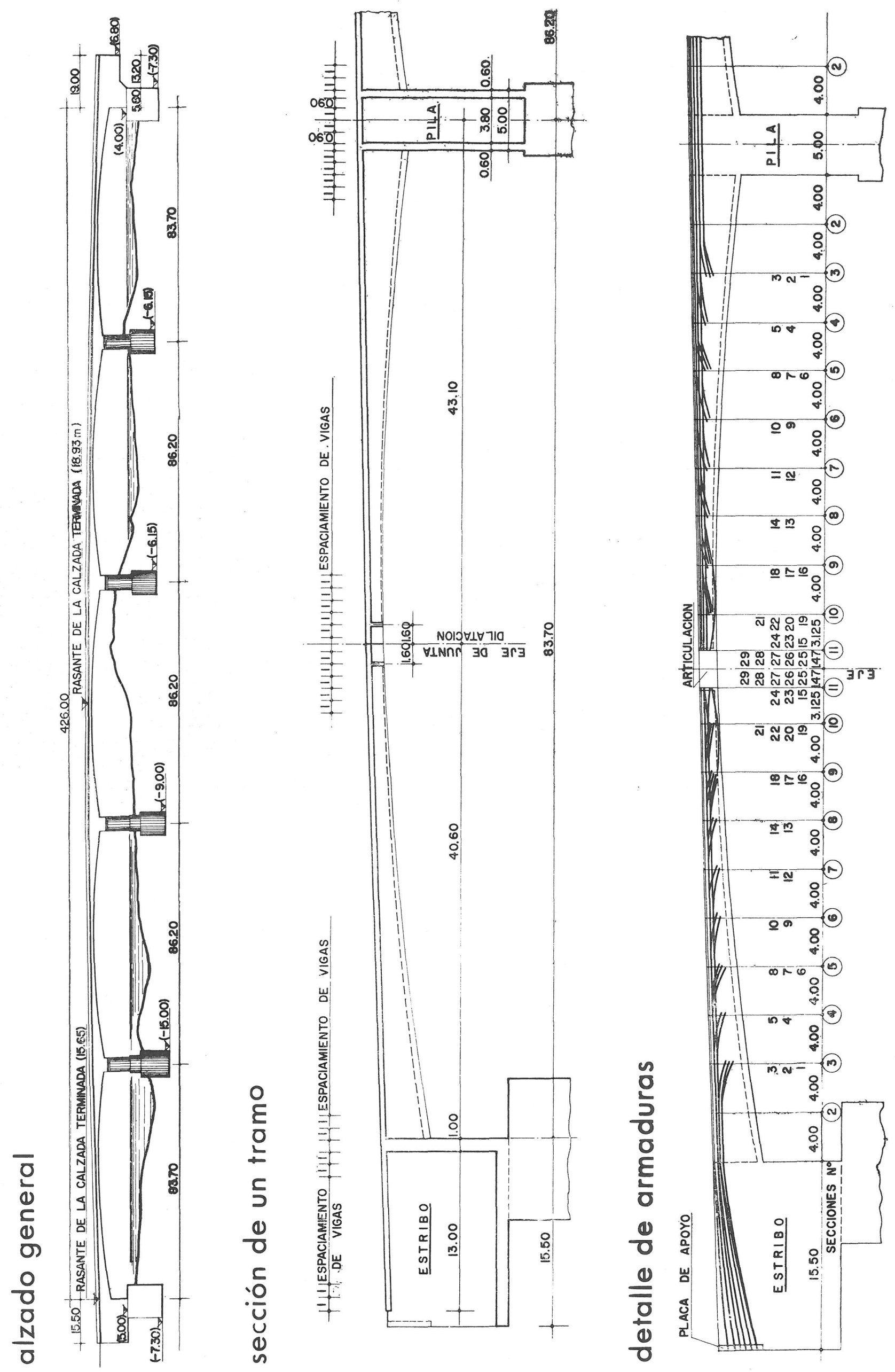


\section{proceso constructivo}
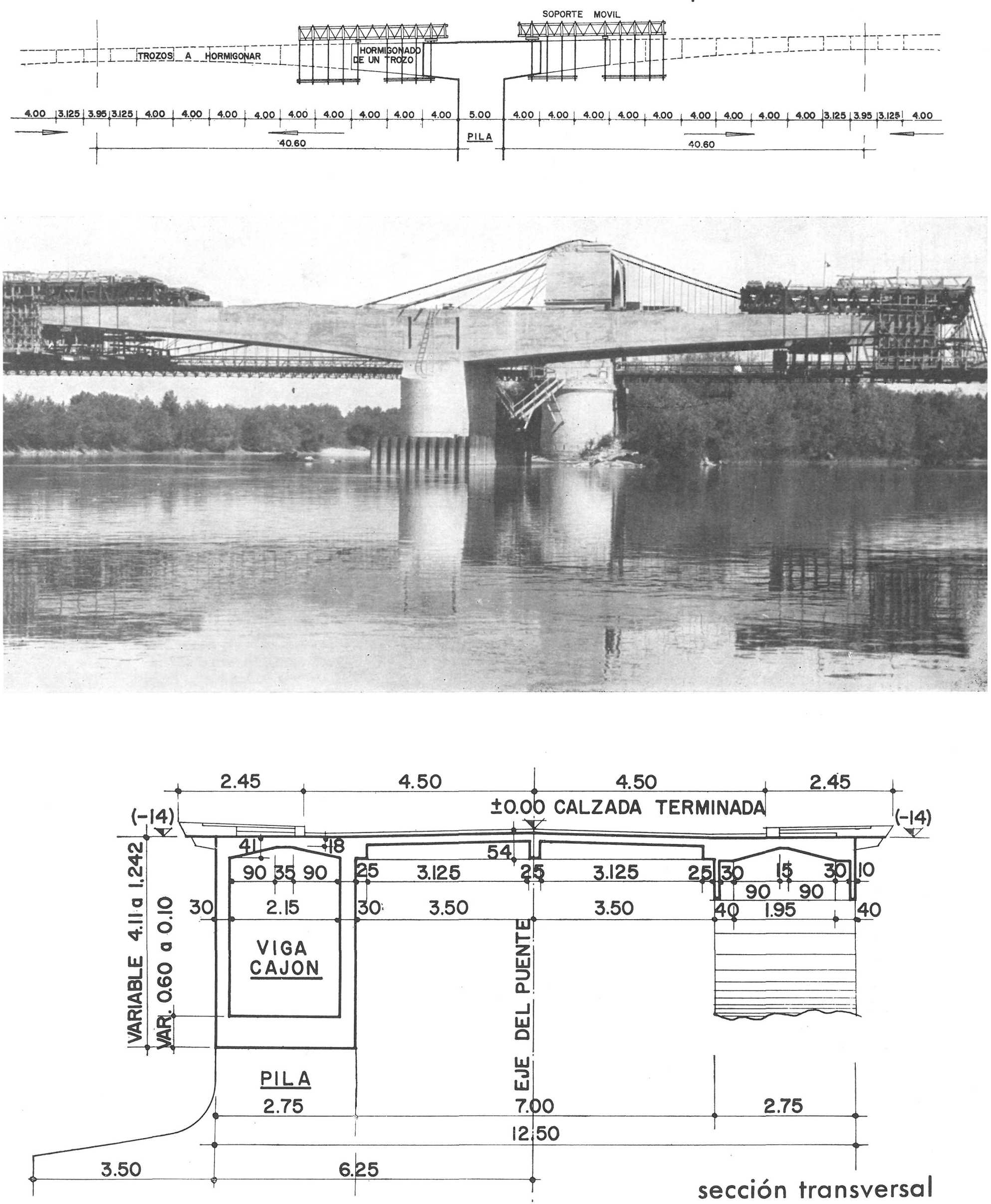


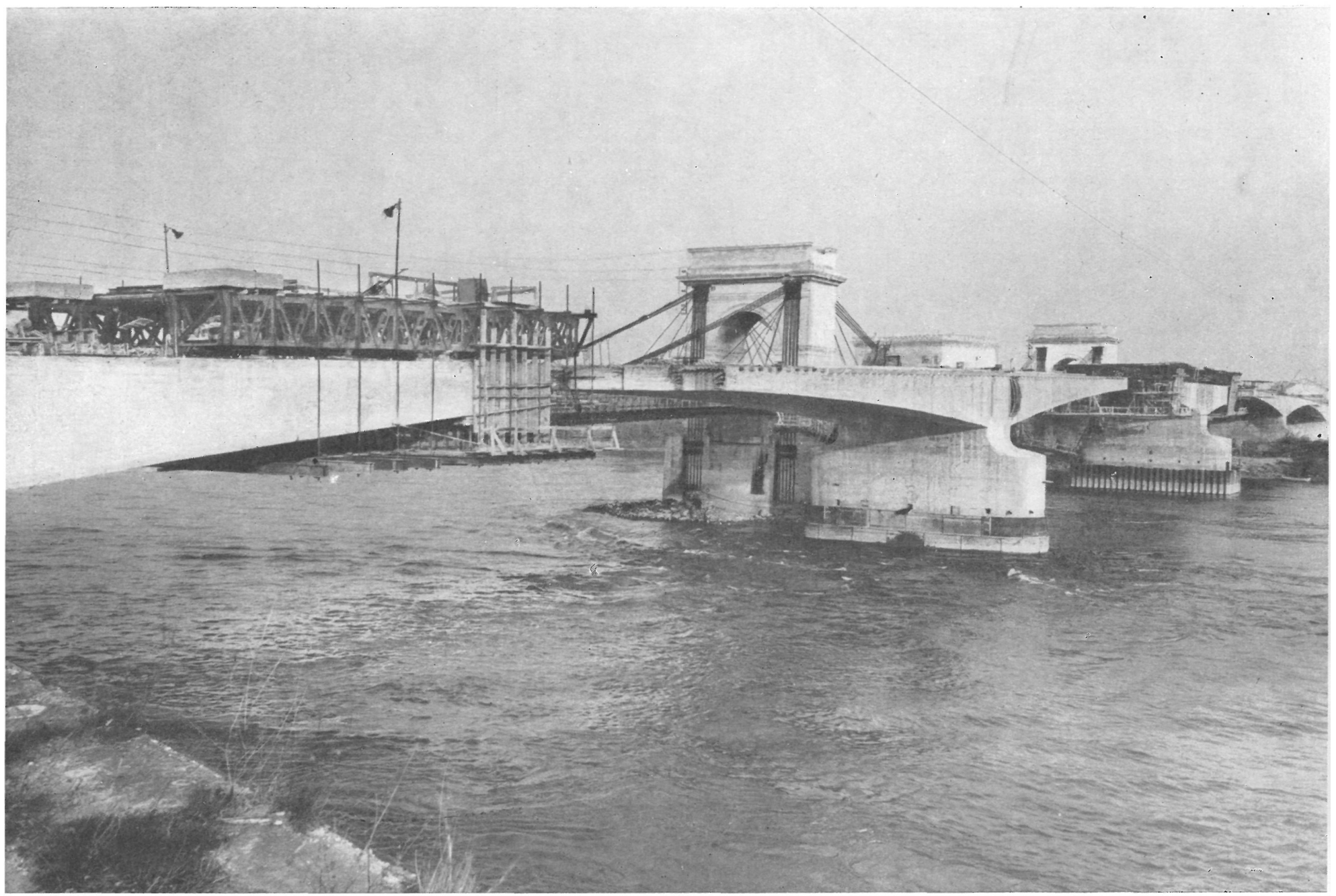

El estribo y primera pila de la parte de Beaucaire se han cimentado sobre cajones metálicos perdidos que se han hundido con aire comprimido. El estribo y las otras tres pilas, del lado de Tarascón, se han cimentado en el interior de ataguías de tablestacas metálicas.

El cuerpo de las pilas, de hormigón armado, está constituído por una sección rectangular vaciada de 12,50 $\times 5,00 \mathrm{~m}$. La parte anterior de las pilas lleva tajamares de sección elíptica.

Cada pila tiene, en su parte inferior, un cajón de hormigón armado, el fondo del cual está constituído por una losa de espesor uniforme de $1 \mathrm{~m}$. Los muros laterales tienen $1 \mathrm{~m}$ de espesor y, en el sentido longitudinal, muros de $275 \mathrm{~m}$ de espesor, sobre los que se anclan los semitramos extremos.

La sección transversal del puente presenta dos vigas cajón espaciadas a 7,00 $\mathrm{m}$ y de 2,75 $\mathrm{m}$ de anchura.

La losa superior del tablero tiene forma de un forjado nervado transversalmente, cuyos nervios se han espaciado a $1,00 \mathrm{~m}$. Una viga longitudinal central y otras dos laterales, de $0,25 \mathrm{~m}$ de anchura y del mismo canto que las viguetas, se encargan de asegurar la rigidez longitudinal del puente.

El canto de las vigas cajón varía de $4,25 \mathrm{~m}$ en la sección de empotramiento a 1,35 $\mathrm{m}$ en la clave. Cada una de las vigas cajón está constituída por dos almas laterales, de espesor constante, de $0,30 \mathrm{~m}$, de un tabique lateral, de espesor variable, de $0,10 \mathrm{~m}$ en la clave a 0,60 en los empotramientos, y de una losa superior, de $0,18 \mathrm{~m}$, que se ha reforzado con dos acartelamientos triangulares de $0,90 \mathrm{~m}$ de anchura y $0,25 \mathrm{~m}$ de canto.

Sobre los $426 \mathrm{~m}$ de longitud total del puente, el extradós está formado por un arco de $6.000 \mathrm{~m}$ de radio. El intradós, en cada uno de los tramos, está constituído por dos arcos de círculo, de $400 \mathrm{~m}$ de radio, que forman en la clave una arista angulosa.

Las vigas cajón y entramado se han pretensado, longitudinal y transversalmente, valiéndose de armaduras, de 65 toneladas de capacidad, de la Sociedad de Grands Travaux de Marseille.

El número de armaduras es variable, y las secciones de mayor cuantía de armaduras de pretensado se hallan sobre las pilas o estribos, donde se han colocado 126 armaduras, 26 por viga y 10 en el entramado.

En la parte central, y a una y otra parte de la articulación, se ha construído de hormigón armado. Cada semitramo se ha realizado trabajando en ménsula y procediendo por trozos sucesivos a partir de cada una de las pilas. Con este fin se instalaron dos soportes móviles, apoyados sobre la parte ya construída y que servían de soporte a los encofrados de los trozos que se iban añadiendo a medida que avanzaba el hormigonado.

La longitud de cada uno de los trozos sucesivos que constituían los avances, que son 10 en total, fue de $4 \mathrm{~m}$ en los nueve primeros elementos. 